\title{
Correspondence
}

\section{Benefit $v$ s potential harm of genome-wide prenatal cfDNA testing requires further investigation and should not be dismissed based on current data}

The field of prenatal screening has rapidly changed as a result of the introduction of cell-free DNA (cfDNA) testing ${ }^{1,2}$. cfDNA testing can be offered as targeted analysis for the three common trisomies or as genome-wide (GW) analysis. GW-cfDNA testing may reveal findings other than trisomies 13, 18 and 21, such as rare autosomal trisomies (RATs) and structural aberrations (SA).

In an Opinion paper published in this Journal, Jani et al. argue that healthcare providers and grant-awarding bodies should hold back on supporting research for GW-cfDNA screening ${ }^{3}$. They raise several concerns regarding GW-cfDNA testing and suggest that an implementation study investigating the additional value of GW over targeted cfDNA testing, such as the Dutch TRIDENT-2 study ${ }^{4}$, may be ethically questionable.

We disagree with holding back on research and, in fact, we argue that research on the clinical benefits and potential harms of GW-cfDNA testing is important to support responsible implementation, and that it can be considered unethical to restrain from it. As scientific data regarding GW-cfDNA testing in an unselected population are currently lacking, further research is essential.

The Netherlands is one of the first countries to perform a nationwide implementation study (TRIDENT-2 study) of GW-cfDNA as a first-tier test offered to all pregnant women ${ }^{4}$. Jani et al. ${ }^{3}$ refer to that study but omit to mention that participants can choose to undergo targeted or GW testing, with the large majority of women $(78 \%)$ preferring GW-cfDNA testing ${ }^{4}$. The fact that the TRIDENT-2 study is a government-controlled implementation study offers the unique opportunity to analyze a large dataset with well-documented numbers on uptake, test performance and invasive follow-up procedures, but also assess the quality of protocolized pre- and post-test counseling and obtain insights into the perspectives of the pregnant women, such as parental anxiety. All study outcomes together will allow the Dutch healthcare policy makers to reach a decision about implementation of cfDNA testing (targeted or GW) as a first-tier screening test in clinical practice, supported by evidence-based research.

Of concern are several misinterpretations by Jani $e t$ al. concerning the TRIDENT-2 study data, especially when it comes to over-interpretation of clinical findings. It is stated clearly in the TRIDENT-2 publication that the reported data are preliminary results and that complete clinical outcome data still need to be analyzed ${ }^{4}$. Jani et al. incorrectly state that only one of the six fetuses with a confirmed RAT had an abnormal phenotype, which is not known yet. Furthermore, they argue that the 29 cases with confirmed fetal SAs could have been discovered by ultrasound. Again, this outcome is not known yet, but their assumption is very unlikely to be true as not all clinically significant additional findings of GW-cfDNA testing (RATs, SAs) are associated with structural ultrasound anomalies ${ }^{5}$. Indeed, not all fetal anomalies can be detected by prenatal ultrasound, especially not at an equally early gestational age. A previous study has shown that $38.6 \%$ of the cases with additional findings detected via cfDNA testing in a cohort of 15626 consecutive pregnancies had no ultrasound anomalies ${ }^{6}$. Lastly, Jani et al. suggest that, in seven cases consistent with maternal (pre)malignancy, the benefit of the discovery was not demonstrated. Again, this statement is premature. We found five cases of hematological malignancy, one of breast carcinoma and one case of a premalignant breast ductal carcinoma in situ ${ }^{4}$. These are medical conditions that are likely to require rapid treatment and can therefore be considered relevant, as shown in previous studies ${ }^{7}$.

Abnormal cfDNA-screening results necessitate invasive follow-up testing. Jani et al. raise the concern that GW-cfDNA testing may lead to a substantial increase in the rate of invasive tests due to discordant positive test results, when the introduction of non-invasive cfDNA testing aimed to reduce this. Although the majority of the RATs and SAs reported in the TRIDENT-2 study could not be confirmed in the fetus after invasive testing, it is important to realize that the overall prevalence of additional findings in a general population is low $(0.36 \%)^{4}$. Therefore, the overall number of invasive tests in The Netherlands since the introduction of GW-cfDNA testing is much lower as compared to that in the era before the TRIDENT studies, when first-trimester combined testing was the sole screening test offered ${ }^{4,5}$.

The results of the TRIDENT-1 study, offering GW-cfDNA testing to high-risk women ${ }^{8}$, and of other studies ${ }^{9}$ have shown that the risk of an adverse pregnancy outcome is increased by $23-45 \%$ due to fetal growth restriction (FGR), structural anomalies or intrauterine fetal demise, even if the additional finding is confined to the placenta (confined placental mosaicism (CPM)). Also, CPM may be a marker for uniparental disomy (UPD) which can have clinical consequences depending on the chromosome involved.

Jani et al. ${ }^{3}$ argue that the incidence of adverse pregnancy outcome is not increased in cases with CPM, except when it involves trisomy 16 . This assumption is based on the findings from one study in which CPMs were identified in chorionic villus samples in an unselected population ${ }^{10}$, that, in our view, cannot be extrapolated to the CPM cases identified by cfDNA testing ${ }^{11}$. It is 
hypothesized that, in cases with CPM, the presence of a trisomy in the placenta alters its function. Pregnancies with CPM have a risk of developing FGR compared to those without CPM, and this is not observed only for trisomy $16^{12}$. The ratio of placental infarcts nearly doubled in cases with CPM compared to chromosomally normal placentas from FGR fetuses ${ }^{12}$.

Finally, Jani et $a l .^{3}$ raise concerns regarding parental counseling and termination of pregnancy after additional findings on GW-cfDNA testing. We agree that both preand post-test counseling is important. In the TRIDENT-2 study $^{4}$, cfDNA testing can only be offered and counseled by counselors, who inform prospective parents about the possibility of uncertain results, such as fetal mosaicism, CPM but also maternal disease. Post-test counseling in cases of findings other than trisomy 21, 18 or 13 is carried out only by clinical geneticists. At post-test counseling, patients are informed about the test result, they are offered follow-up diagnostic testing to assess the clinical significance of the finding and it is clarified that termination of pregnancy cannot be offered before such testing has been performed. Assessment of patient perspectives, including psychological harm as well as the quality of counseling and decision-making, are important outcomes of the TRIDENT-2 study ${ }^{4}$.

In conclusion, the clinical consequences of additional findings by GW-cfDNA testing require further research and the benefits need to be critically balanced against potential harms. Healthcare policymakers worldwide should encourage research that thoroughly and critically assesses all aspects of GW-cfDNA testing. The Dutch TRIDENT studies are good examples of such research, and preliminary data from these studies should not be used to draw far-fetched conclusions.

\section{Disclosure}

All authors are affiliated with the Dutch NIPT Consortium that initiated the TRIDENT studies in The Netherlands. The TRIDENT studies are supported by a grant from The Netherlands Organization for Health Research and Development (ZonMw, No. 543002001).

M. N. Bekker ${ }^{1 *(D)}$, L. Henneman ${ }^{2}$, M. V. E. Macville ${ }^{3}$, E. A. Sistermans ${ }^{2}$ and R. J. H. Galjaard ${ }^{4}$

${ }^{1}$ Department of Obstetrics and Gynaecology, University Medical Center Utrecht, Utrecht University, Utrecht, The Netherlands;

${ }^{2}$ Department of Clinical Genetics, Amsterdam UMC, Vrije Universiteit Amsterdam, Amsterdam, The Netherlands;

${ }^{3}$ Department of Clinical Genetics, Maastricht UMC+, Maastricht, The Netherlands;

${ }^{4}$ Erasmus Medical Center, Erasmus University, Rotterdam, The Netherlands *Correspondence. (e-mail:m.n.bekker-3@umcutrecht.nl)

DOI: 10.1002/uog.22030

\section{References}

1. Gil MM, Galeva S, Jani J, Konstantinidou L, Akolekar R, Plana MN, Nicolaides $\mathrm{KH}$. Screening for trisomies by cfDNA testing of maternal blood in twin pregnancy: update of The Fetal Medicine Foundation results and meta-analysis. Ultrasound Obstet Gynecol 2019; 53: 734-742.

2. Gil MM, Accurti V, Santacruz B, Plana MN, Nicolaides KH. Analysis of cell-free DNA in maternal blood in screening for aneuploidies: updated meta-analysis. Ultrasound Obstet Gynecol 2017; 50: 302-314.

3. Jani JC, Gil MM, Benachi A, Prefumo F, Kagan KO, Tabor A, Bilardo CM, Di Renzo GC, Nicolaides KH. Genome-wide cfDNA testing of maternal blood. Ultrasound Obstet Gynecol 2020; 55: 13-14.

4. van der Meij KRM, Sistermans EA, Macville MVE, Stevens SJC, Bax CJ, Bekker MN, Bilardo CM, Boon EMJ, Boter M, Diderich KEM, et al. TRIDENT-2: National Implementation of Genome-Wide Non-Invasive Prenatal Testing as a First-Tier Screening Test in the Netherlands. Am J Hum Genet 2019; 105: 1091-1101.

5. Oepkes D, Page-Christiaens GC, Bax CJ, Bekker MN, Bilardo CM, Boon EM, Schuring-Blom GH, Coumans AB, Faas BH, Galjaard RH, Go AT, Henneman L, Macville MV, Pajkrt E, Suijkerbuijk RF, Huijsdens-van Amsterdam K, Van Opstal D, Verweij EJ, Weiss MM, Sistermans EA; and for the Dutch NIPT Consortium. Trial by Dutch laboratories for evaluation of non-invasive prenatal testing. Prenat Diagn 2016; 36: 1083-1090.

6. Yao H, Gao Y, Zhao J, Zhang R, Xu H, Hu H, Luo Y, Yuan Y, Fu M, Zhang $\mathrm{H}$, Jiang $\mathrm{H}$, Wang W, Yang H, Wang J, Liang Z, Chen F. Genome-wide detection of additional fetal chromosomal abnormalities by cell-free DNA testing of 15,626 consecutive pregnant women. Sci China Life Sci 2019; 62: $215-224$.

7. Amant F, Verheecke M, Wlodarska I, Dehaspe L, Brady P, Brison N, Van Den Bogaert K, Dierickx D, Vandecaveye V, Tousseyn T, Moerman P, Vanderstichele A, Vergote I, Neven P, Berteloot P, Putseys K, Danneels L, Vandenberghe P, Legius E, Vermeesch JR. Presymptomatic Identification of Cancers in Pregnant Women During Noninvasive Prenatal Testing. JAMA Oncol 2015; 1: 814-819.

8. Van Opstal D, van Maarle MC, Lichtenbelt K, Weiss MM, Schuring-Blom H, Bhola SL, Hoffer MJV, Huijsdens-van Amsterdam K, Macville MV, Kooper AJA, Faas BHW, Govaerts L, Tan-Sindhunata GM, den Hollander N, Feenstra I, Galjaard RH, Oepkes D, Ghesquiere S, Brouwer RWW, Beulen L, Bollen S, Elferink MG, Straver R, Henneman L, Page-Christiaens GC, Sistermans EA. Origin and clinical relevance of chromosomal aberrations other than the common trisomies detected by genome-wide NIPS: results of the TRIDENT study. Genet Med 2018; 20 480-485.

9. Pertile MD, Halks-Miller M, Flowers N, Barbacioru C, Kinnings SL, Vavrek D, Seltzer WK, Bianchi DW. Rare autosomal trisomies, revealed by maternal plasma DNA sequencing, suggest increased risk of feto-placental disease. Sci Transl Med 2017; 9: eaan1240.

10. Grati FR, Ferreira J, Benn P, Izzi C, Verdi F, Vercellotti E, Dalpiaz C, D’Ajello P, Filippi E, Volpe N, Malvestiti F, Maggi F, Simoni G, Frusca T, Cirelli G, Bracalente G, Re AL, Surico D, Ghi T, Prefumo F. Outcomes in pregnancies with a confined placental mosaicism and implications for prenatal screening using cell-free DNA. Genet Med 2020; 22: 309-316.

11. Sistermans EA, Van Opstal D, Bekker MN, Pertile MD. The clinical benefit of genome-wide cfDNA testing cannot be extrapolated from CVS data. Genet Med 2020; 22: 657-658.

12. Meler E, Sisterna S, Borrell A. Genetic syndromes associated with isolated fetal growth restriction. Prenat Diagn 2019. DOI: 10.1002/pd.5635. 